\title{
WHERE HAVE ALL THE LILIES GONE?: A POPULATION STUDY
}

BONNIE LAWRENCE, RR 6, Box 286, Saskatoon, SK. S7K 3J9 and ANNA LEIGHTON, 328 Saskatchewan Crescent West, Saskatoon, SK. S7M OA4

John Macoun describes the prairie at the north end of Last Mountain Lake ("Long Lake"), Saskatchewan in the first week of July 1879 as follows: "Flowers are a most conspicuous feature of the prairie ... Sometimes, lilies (Lilium philadelphicum) are so abundant that they cover an acre of ground, bright red. At others, they are mixed with other liliaceous plants, such as Zygadenus glaucus [White Camas] and form a ring around the thickets which we passed." 3

In stark contrast to Macoun, we tend to think of the lily as rare today, perhaps even endangered. Yet, as recently as 1941, when the Western Red Lily (Lilium philadelphicum var. andinum, also known as the Prairie or Western Wood Lily), was chosen as our provincial flower, it was selected because of its abundance, as well as its flamboyant beauty. Has something happened to lily populations in recent years? Why do lilies bloom in such profusion some years and then seem to disappear? It was questions such as these that inspired us to study lily populations.

The Study We began our study in 1993 and 1994 by tagging a small number of flowering lilies in two field locations where the plants were blooming - the edge of an alkali slough east of the Strawberry Hills, $30 \mathrm{~km}$ east of Saskatoon (Sites 1 and 2) and in an upland meadow near the South Saskatchewan River, southwest of Pike Lake (Site 3). In
1995 and 1996, we set up study plots of $12 \mathrm{~m}^{2}$ each in these locations which allowed us to plot accurately the location of individual plants for long-term observation. We also expanded the study in 1995 to include several sites at Last Mountain Lake National Wildlife Area (LMLNWA) where we could compare lily populations in burned and unburned habitats.

Each site was visited at least twice a year. One visit was during the flowering period in late June early July to see which of the tagged lilies produced flowers and to tag any new plants that had appeared. Another visit was in late summer to observe what happened over the growing season to the plants that had flowered earlier. We were particularly interested in how many flowering plants survived to produce seed pods, what happened to those that flowered but failed to set seed, and whether plants that flowered one year reappeared as flowering plants the next year.

\section{Different Forms of the Lily Plant} When we began the study we were able to recognize lilies only when they were in flower, but while making observations of lilies at our sites, we came to recognize two other forms of the plant. The "vegetative" form is a non-flowering plant consisting of a delicate upright stem with slender leaves and no signs of flower development. The other non-flowering form has a taller, more robust stem 


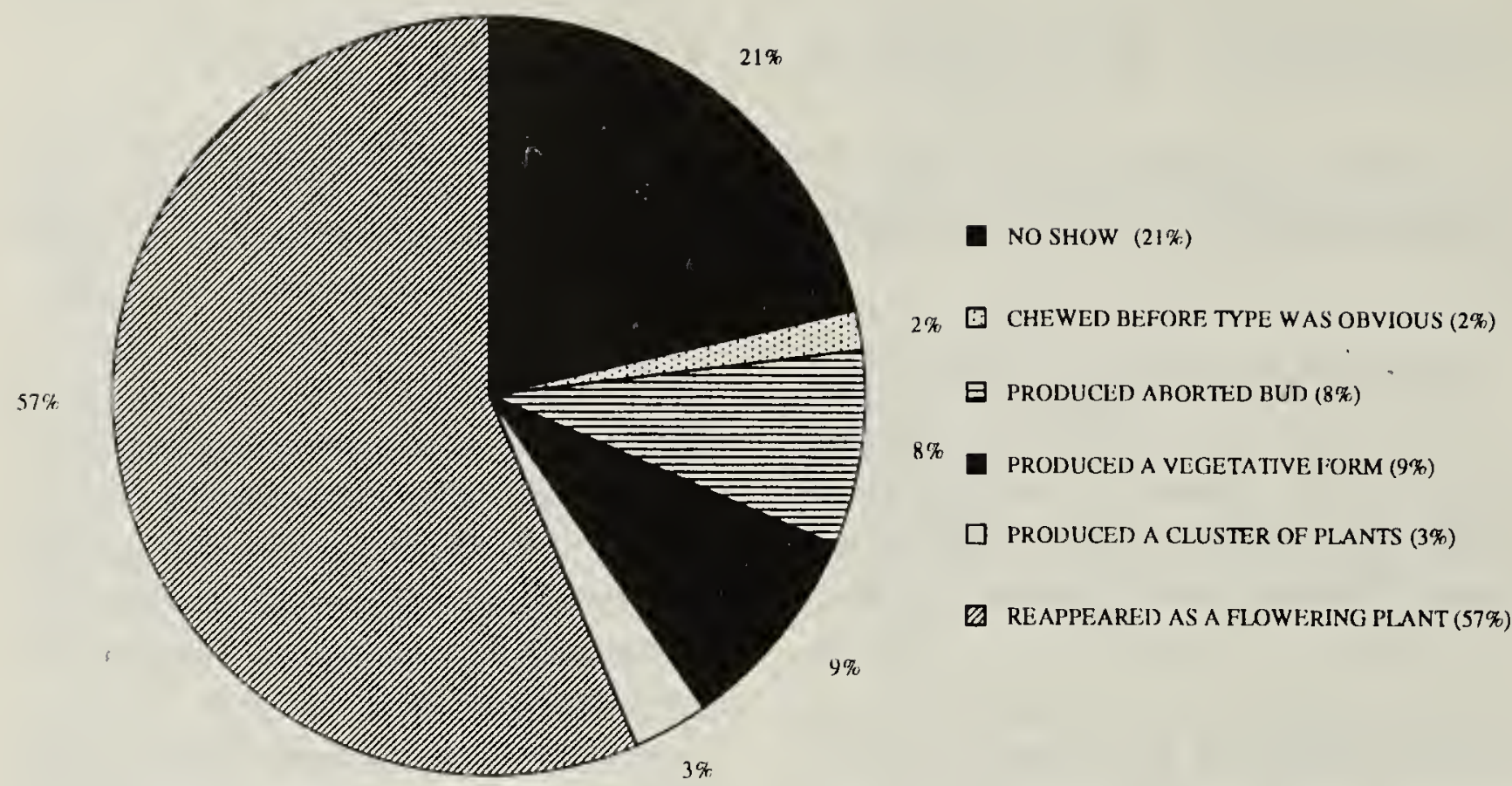

Figure 1. Fate of flowering plants from one year to the next $(n=122)$.

than the vegetative form and what looks like a vestigial, undeveloped flower bud at the top of the terminal whorl of leaves. We call this form "aborted bud" because it appears that the plant was ready to send up a flowering stem but stopped the flowering process at an early stage.

In our survey of what happens to lilies from one year to the next, we discovered that individual lilies can appear in different forms in subsequent years. In addition, a plant may not grow at all for a year or two and then reappear. Slightly over half of the 122 flowering lilies for which we have data for two or more years, flowered again in the second year (Fig. 1). A little less than a quarter did not grow at all in the second year (no show), and the remainder grew as vegetative or aborted bud plants. A few of the individual flowering plants reappeared as tightly spaced "clusters of plants" that were composed of a variety of vegetative, aborted bud and/or flowering forms. We lack information on a small percentage of plants that reappeared but had their stems cut off near the base by mammals (these plants are referred to as "chewed") before we could determine their form. We don't know what causes the plants to change form from year to year. We do know that practically every sequence of forms occurs, including going from a vegetative form to a flowering plant and from an abortedbud plant to a vegetative form, in addition to all the transformations shown in Fig. 1.

Dynamic Lily Populations These changes in form from one year to the next illustrate the dynamic nature of lily populations. A different subset of individuals flowers each year. Some that have flowered for several years disappear completely and lilies not previously seen in any form, appear as flowering plants. Of the 78 flowering plants tagged at four of our sites in 1995, 17 failed to reappear in 1996 but there were 94 occurrences of new flowering plants.

Thus, in any given year, the visual impression of the number of lilies 


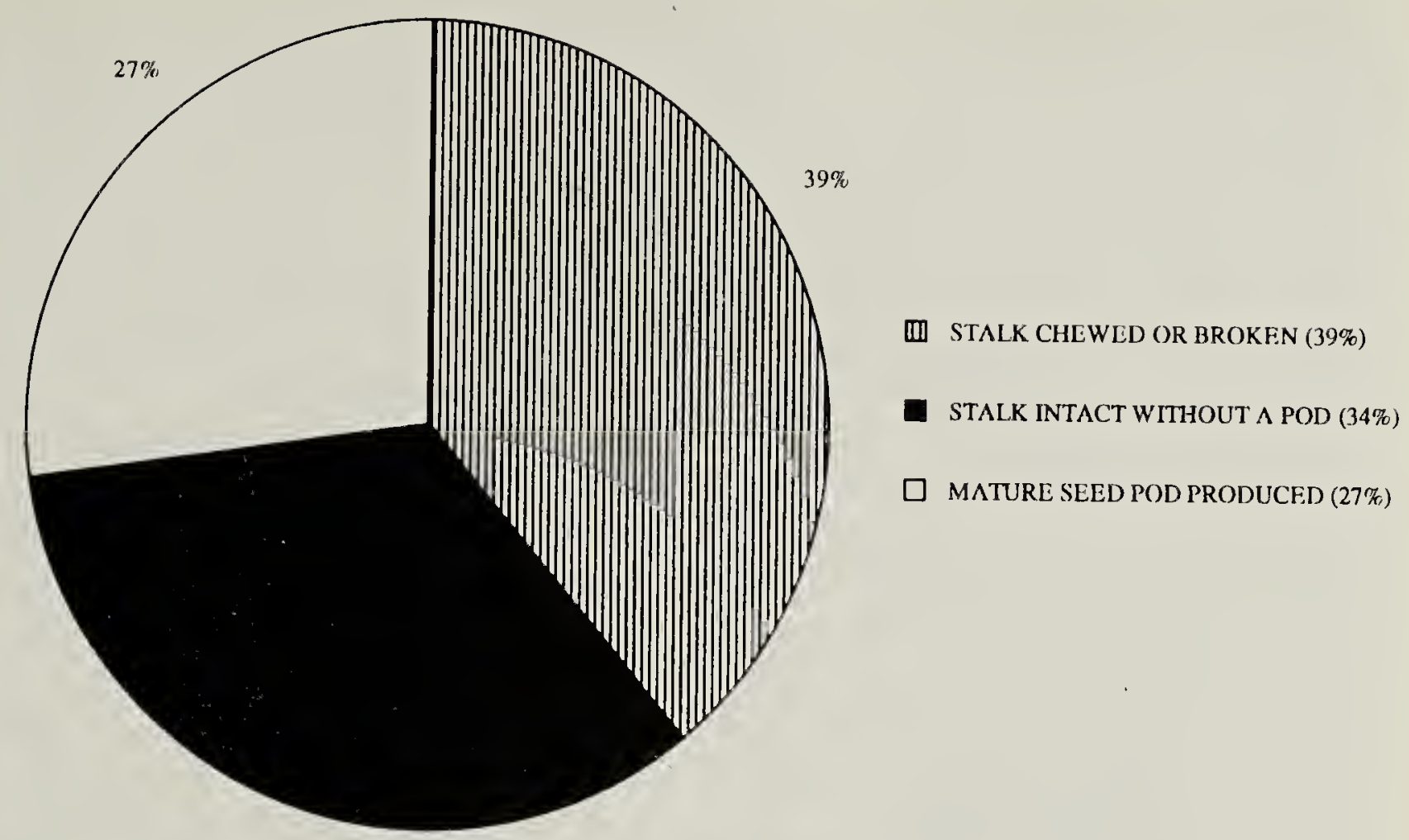

Figure 2. Fate of flowers within one season $(n=291)$.

blooming does not give an accurate measure of the total lily population. Vegetative and aborted bud forms tend to be overlooked by the casual observer and some plants persist from year to year as bulbs. In good lily years, when conditions are right for flowering, many of these plants will flower in bright abundance; in poor years, there may be no flowering plants at all. An example of an apparent disappearance of a lily population was observed by Doris Silcox in 1985 and 1986, following a two-year decline in the number of flowers. In 1987, the lilies in this population started to bloom again and she noted that, "The lily patch at the roadside made a remarkable recovery with 43 red lilies and three yellow lilies." 5

\section{Production of Seed Pods Flowers} are the most noticeable part of the lily plant, but long-term survival of the population depends on successful seed production. Our observations on what happened to individual flowering plants in the course of the growing season suggest that lilies have a low rate of reproductive success as measured by production of mature pods (Fig. 2). Fewer than one-third of the 291 flowering plants for which we have information produced mature seed pods. Slightly more than one-third of the flowering stalks were chewed off or broken before the pods developed and almost one-third retained the flowering stalk but failed to produce a pod. In some cases, there was no sign of any pod development; in others, a small, desiccated pod failed to mature.

The high proportion of flowering stems chewed off before setting seed is a reflection of how palatable lilies are to mammals. The lilies in our plots were eaten primarily by rodents, judging by the height of the stalks left behind after chewing: around $6.5 \mathrm{~cm}$ at Site 2 and $12 \mathrm{~cm}$ at LMLNWA. Deer are also known to eat lilies, especially the buds, ${ }^{2}$ leaving a taller stalk. Chewing by small mammals appears systematic and thorough, but never affected all the lilies in a population. It can however, significantly decrease the overall amount of seed production. At Site 2, $67 \%$ of the 49 flowering plants were chewed off in 1995.

Small mammal activity seems to 


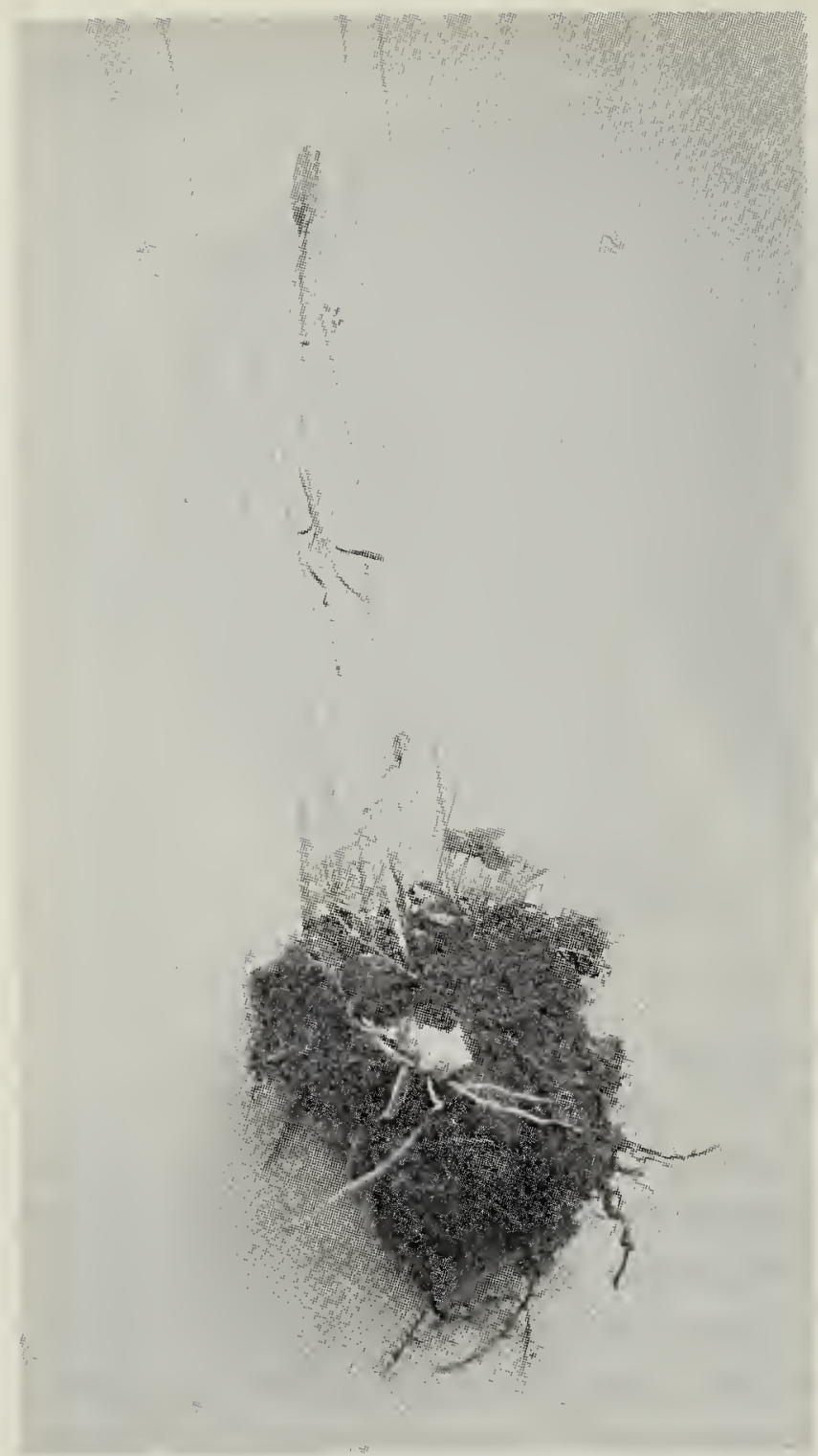

Figure 3. Exposed bulb with intact lily stalk. Anna Leighton

be related to the density of vegetative cover. At two LMLNWA sites with dense vegetation cover, $88 \%$ of the 52 flowering stalks were chewed off in 1995 and 1996. In contrast, there was no evidence of small mammals in a LMLNWA site that had been burned in the spring of 1996 , removing the vegetative cover.

Vegetative Reproduction Lilies, like most plants, are not limited to reproduction by seed, and in fact have tremendous potential to reproduce vegetatively. Mature lily bulbs are composed of several dozen easily detached bulb scales, each of which can produce a new plant. The bulb is about $5 \mathrm{~cm}$ below the soil surface (Fig. 3). Lily bulbs often have an older portion from which the base of the current flowering stalk arises and a newer portion from which the next stalk will grow (Fig. 4). The number and the form of the bulb scales removed from each of these portions is shown in Figure 5. Note that some of these scales consist of two parts (jointed scales) and that both parts can grow a new plant. Jointed scales are particularly important in vegetative reproduction, as the top part detaches readily with minimal disturbance. A young lily plant growing from a non-jointed bulb scale is shown in Figure 6.

Rodents and Lily Bulbs It has been reported in the literature that voles eat lily bulbs. Stuart Criddle described stockpiling of lily bulbs by the Prairie Vole, Microtus ochrogaster minor. "The [vole's] store room was only about a third full of what appeared to be lily bulbs. However this was not the case, as when the contents were sorted out and counted, I found it to be composed of the following; 1176 lily bulbs (Lilium philadelphicum); 678 wild onion bulbs (Allium stellatum); 583 pieces of the rhizomes of sunflower (Helianthus rigidus); 417 buds and pieces of the taproot of pasque-flower (Pulsatilla ludoviciana)" in addition to bits and pieces of several other plants. The lily bulbs made up $79 \%$ of 2648 grams of the total plant material. ${ }^{2}$

John Richardson lends support to this observation when he says that Lilium philadelphicum is "termed by the Crees, Appecooseesh-ootchoepeh (Mouse-root) because the common mouse of the country, a species of Campagnol, feeds upon its scaly bulb." ${ }^{4}$

Observations at Site 2 led us to wonder about the effects of pocket gophers on lily populations. These animals tunnel underground in search of roots to eat and store for 


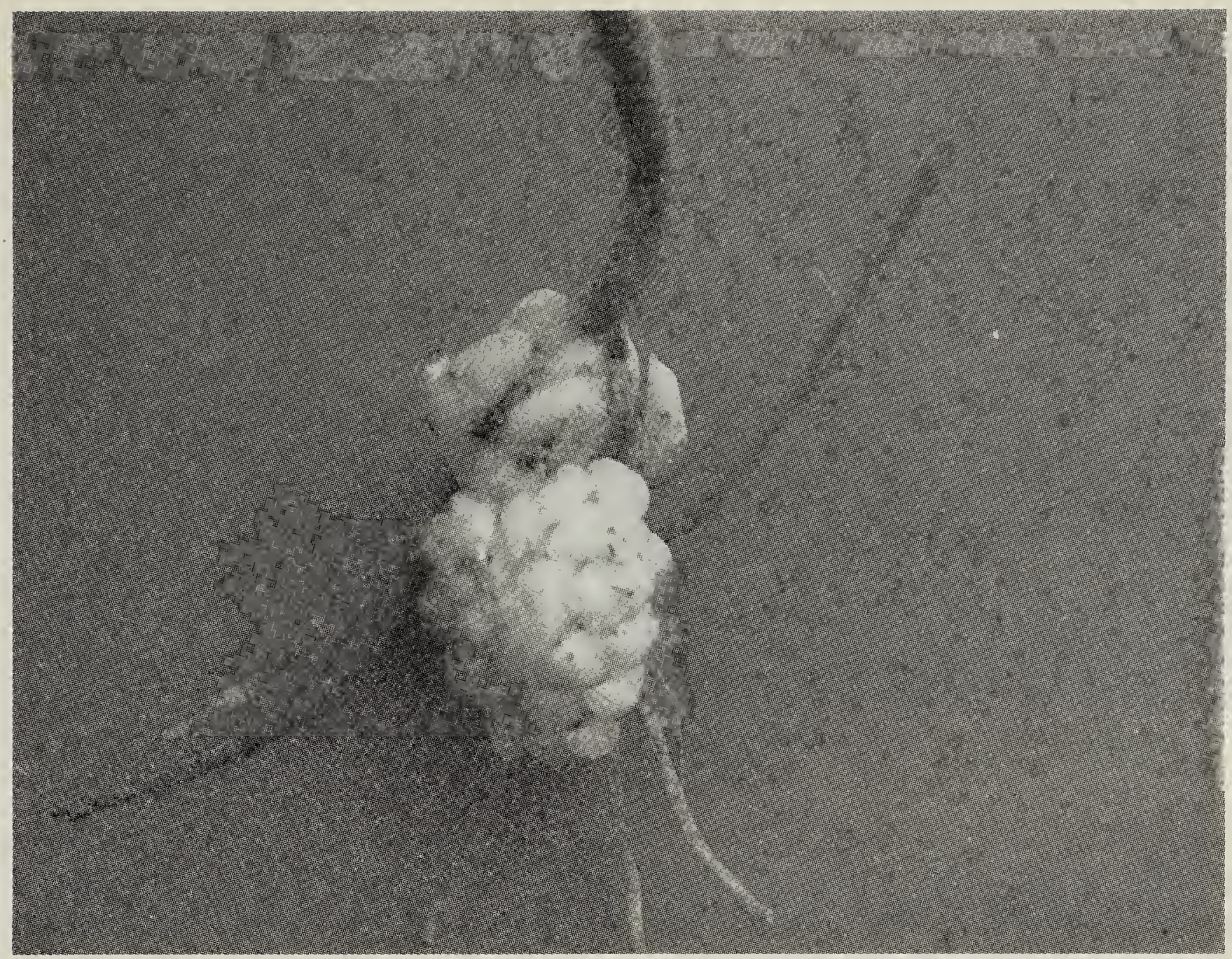

Figure 4. Same bulb with soil removed. Left hand arrow indicates the older portion of the bulb with an attached flowering stalk. Right hand arrow indicates the newer portion of the bulb. Anna Leighton

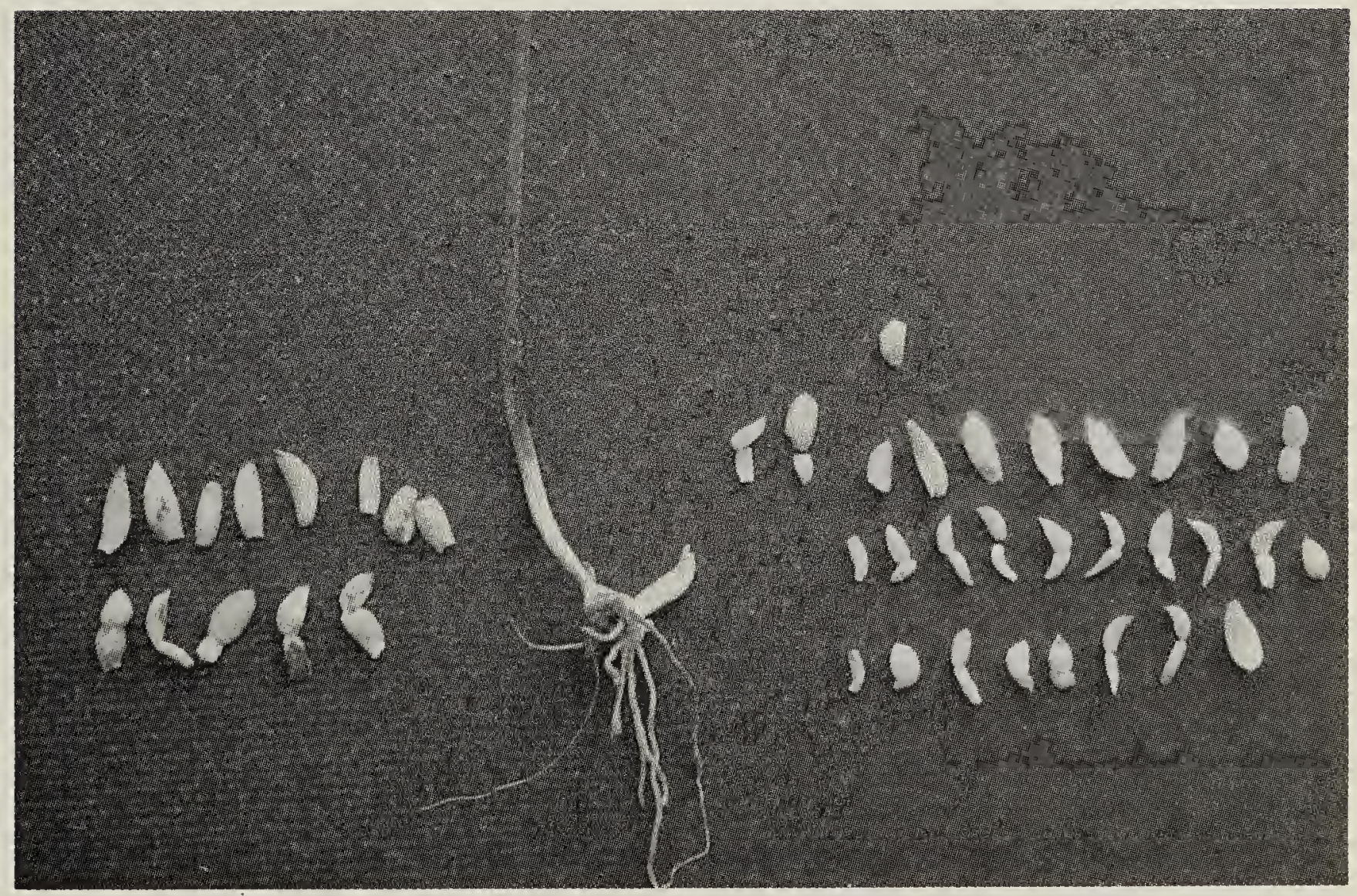

Figure 5. Bulb scales removed from the same bulb. Bulb scales of the older portion are on the left; those of the newer portion, on the right. The arrow indicates a row of jointed scales. Anna Leighton 


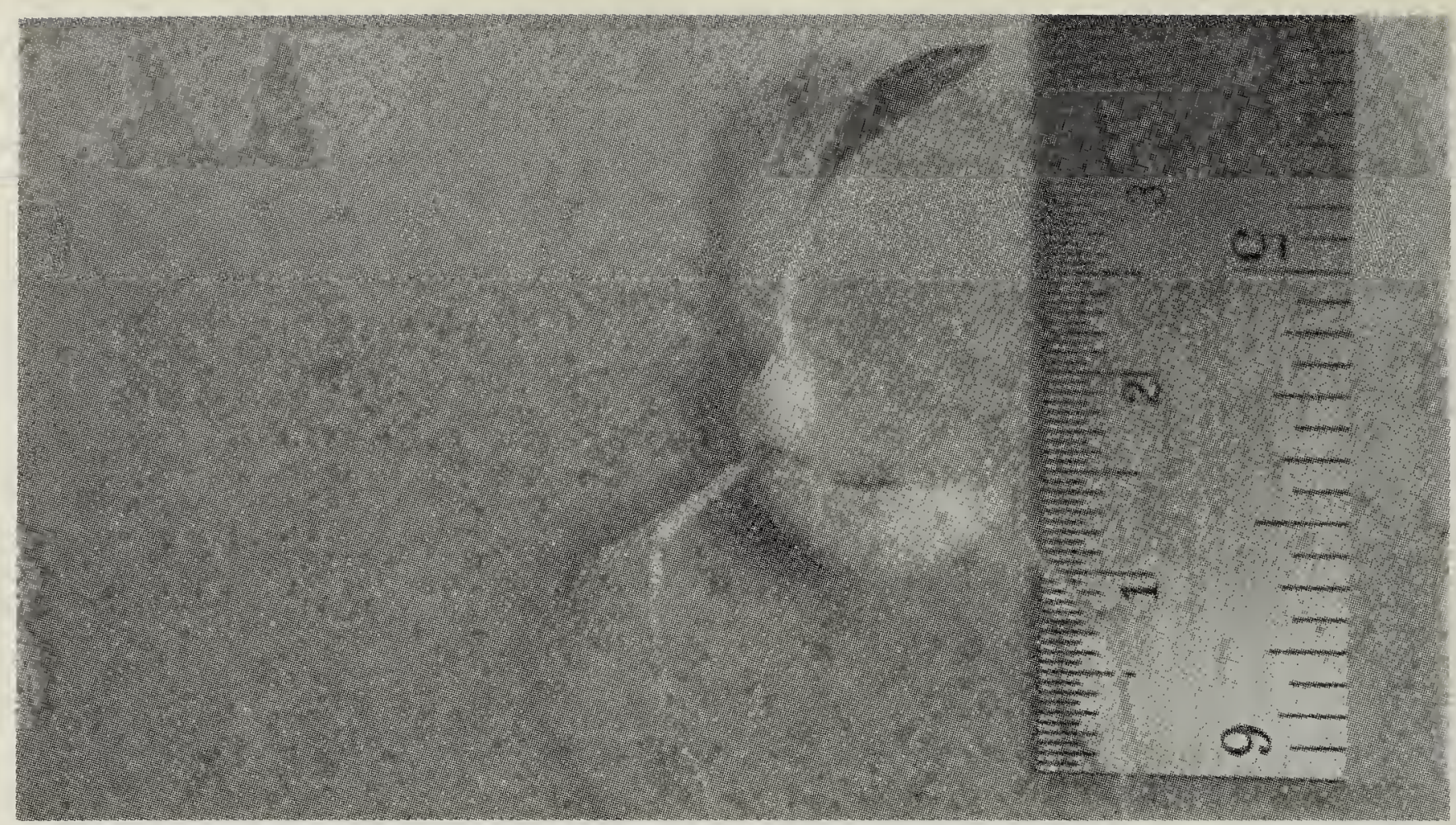

Figure 6. Young lily plant growing from a non-jointed bulb scale. Anna Leighton

winter. Criddle's excavations of five stores of at least three different pocket gophers in late October and early November did not reveal any lily bulbs, but he observes that pocket gophers will eat whatever is growing near their burrows and that "there is little actual preference in the selection of food, but that the roots are taken as encountered."1

Pocket gophers had burrowed extensively in and around the plot at Site 2 in 1993. Two years later, we noted a large number of new plants, one-half of which were vegetative and could very likely have grown from detached bulb scales in the intervening two years. This plot had the highest density of lilies (an average of eight lilies per metre square in 1995) that we have observed in any of our plots. We speculate that if pocket gophers were eating or transporting bulbs underground, the detachable scales would have broken off and, once separated from the main bulb, would have grown into new plants.

Conclusion This article presents observations on the natural history of the Western Red Lily that help explain fluctuations in numbers of flowering plants in a given population, namely the change in form of lily plants from year to year and the chewing of plants by mammals. In terms of the overall impression of the number of lilies flowering in Saskatchewan in any one year, other factors are important. One of these is weather. Over the last three years, the number of lilies counted in three sites has steadily increased, an increase which we attribute, in part, to increased moisture at certain times of the year.

Probably the most important factor to affect lilies in Saskatchewan, however, is the destruction of native prairie by cultivation. Lilies increase and decrease in response to other factors, but cultivation simply eliminates whole populations. In addition, the now scattered remnants of prairie present problems for management of plants like the lily which may require periodic disturbances such as fire for long-term survival.

We are just beginning to gain some understanding of this plant's 
some understanding of this plant's life history and how it survives in Saskatchewan. There is a great deal more to be learned, such as how long individual plants live, at what age or stage of development they begin to flower and what triggers the flowering process. We plan to continue our field studies for another six years and have already begun greenhouse propagation experiments and a program of planting lilies of known age back into the wild for observation. This research should provide information about our provincial flower that will be both interesting and important in managing areas with existing lily populations.

We would like to close with a quote by the Earl of Southesk which describes a bloom of lilies near Qu'Appelle in 1859: "Sometimes acres and acres were covered with intermingled masses of the orange lily and the pendulous blue-bell, the whole of them so short of stem that the glory of the flowers combined with the rich greenness of their leaves, and it seemed as if a vast oriental carpet had been thrown upon the ground." 6

We welcome comments from readers about lilies. We can be reached by mail using either of the authors' addresses at the beginning of this article, by e-mail at fleighto@ eagle.wbm.ca or by phone at 373$8674(\mathrm{BL})$ or 665-6074 (AL).
Acknowledgements We gratefully acknowledge the financial support for this project from Nature Saskatchewan through a Members' Initiatives Grant and the collaboration of the Last Mountain Lake National Wildlife Area staff. We would also like to thank Dr. Taylor Steeves for his advice and support throughout the study and for reviewing the manuscript for publication.

1. CRIDDLE, STUART. 1930. The prairie pocket gopher, Thomomys talpoides rufescens. Journal of Mammology 11(3): 265-280.

2. 1947. Microtus minor and the Prairie Lily. Canadian Field-Naturalist 61:116.

3. MACOUN, JOHN. 1979. Autobiography of John Macoun, M.A. Ottawa Field-Naturalists' Club, Ottawa.

4. RICHARDSON, JOHN. 1823. Botanical appendix. In: FRANKLIN, JOHN. 1823. Narrative of a journey to the polar sea, in the years 1819-20-21-22. John Murray, London.

5. SILCOX, DORIS and VERNON L. HARMS. 1989. The Yellow Immaculate Lily in Saskatchewan and adjacent Manitoba, and its persistence in native lily patches. Blue Jay 47: 6973.

6. SOUTHESK, JAMES CARNEGIE. 1875. Saskatchewan and the Rocky Mountains: a diary and narrative of travel ... in 1859 and 1860. Edinburgh. Cited in DOWNIE, MARY ALICE and MARY HAMILTON. 1980. 'and some brought flowers,' Plants in a new world. Toronto University Press, Toronto. 